\title{
Poesía indígena actual: textos que se cantan susurrados en sus lenguas y textos bilingïes que se leen
}

Current indigenous poetry: texts that are sung whispered in their languages And bilingual texts that are read

\section{Claudia Rodríguez Monarca ${ }^{1}$}

Universidad Austral de Chile, Valdivia

\section{RESUMEN}

Referirse a la poesía indígena actual supone tomar en cuenta la variable de la heterogeneidad no solo de los textos, sino también de los modelos de textos que subyacen en las distintas propuestas poéticas. A pesar de esa variedad, proponemos que la poesía indígena actual se canaliza a través de dos tipos de modelos textuales disponibles y vigentes, repertorios que están operando en las distintas culturas, uno de carácter defensivo (esto es, de resistencia y repliegue intracultural) y otro transdiscursivo (de diálogo y despliegue intercultural e interdisciplinar). Los poetas suelen asumir ambas actitudes y transitar de un modelo a otro, desplazamiento propio de los procesos de reterritorialización (simbólica, cultural y geográfica) que les ha tocado experimentar. El corpus considera producciones poéticas andinas actuales (quechua, kichwa, aimara), amazónicas (tikuna, okaína, uitoto, camentsá, ashánica, shuar, bora), guaraní y mapuche.

\section{PALABRAS CLAVE}

Literatura indígena, modelos textuales, repertorio, defensivo, transdiscursivo

\section{ABSTRACT}

Refer to poetry current indigenous means to take into account the variable of heterogeneity not only texts, but also of those models of texts that underlie in the

1 Es profesora de Castellano, magíster en Literatura y doctora en Teoría Literaria y Literatura por la Universidad de Oviedo, España. Desde 2000, es académica de la Universidad Austral de Chile, Valdivia. Su especialidad es poesía hispanoamericana y literaturas indígenas. 
different proposals poetic. In spite of that variety, we propose that the poetry indigenous curren is channeled through two types of models textual available and current, one of defensive nature (that is, of resistance and intra-cultural withdrawal) and another transdiscursivo (of dialogue and intercultural and interdisciplinary deployment). Poets often assume both attitudes and move from one model to another, own displacement of the processes of reterritorialización (symbolic, cultural and geographic) that they have experienced. The corpus considers current Andean poetic productions (Quechua, Kichwa, Aymara), Amazonian (tikuna, okaína, uitoto, camentsá, ashánica, shuar, bora), Guarani and Mapuche.

\section{KEYWORDS}

Indigenous literature, repertoire, defensive, transdiscursivo

\section{Introducción ${ }^{2}$}

Un libro ardiendo en llamas es triste como puma herido anaconda sin piel cielo sin nubes río sin piedras y sin peces árbol sin musgo.

Es cascada sin Arutam...
Yo, indiecito, que me cruzo en tu camino no; porque no hable español y haga utillaje de la mímica, el gesto y la guturación sea un incomunicado; también te ofrezco un follaje de idiomas.

mi herencia para ti son las voces de la selva...

\section{María Clara Sharupi}

Efraín Miranda

Los epígrafes que anteceden estas palabras (de una poeta shuar y un poeta aimara) sugieren nuestra propuesta de lectura de la poesía indígena, que supone tomar en cuenta la variable de la diversidad no solo de los textos, sino también de los modelos de textos que subyacen en las distintas poéticas; por lo tanto, no debiera remitir a un corpus homogéneo de textos ni a la simplificación y reducción de un grupo de naciones y culturas bajo el concepto de lo indígena (atravesado por el argumento de «unidad»), sino a una pluralidad que incorpora sistemas literarios «heterogéneos» que revelan la disgregada realidad de la que surgen. Antonio Cornejo Polar (1982) señala que la pluralidad requiere ser aunada bajo un

2 El artículo es parte del proyecto Fondecyt 1141007 «Reterritorialización en las literaturas andino-amazónicas: poéticas y enunciaciones heterogéneas en confluencia», del que soy investigadora responsable. 
criterio histórico que posibilite la totalidad, y que, a pesar de las diferencias y las contradicciones, resulte ser armónica. Para este autor, la totalidad necesita de esas contradicciones, ya que «parte de ellas para hacer inteligible un proceso literario que nunca será menos que la sociedad que lo produce» (p. 49). De esta manera, da cuenta de la complejidad de la realidad latinoamericana que abre el abanico hacia lo plural, visibilizando en la escena literaria la diversidad de manifestaciones artísticas textuales de las distintas culturas, desconocidas hasta entonces como sistemas literarios representativos y válidos en sus aportes estéticos.

En el presente artículo proponemos que la poesía indígena actual se canaliza a través de dos tipos de modelos textuales disponibles y vigentes, repertorios que están operando en las distintas culturas, uno de carácter defensivo (esto es, de resistencia y repliegue intracultural) y otro transdiscursivo (de diálogo y despliegue intercultural e interdisciplinar). Los poetas suelen asumir ambas actitudes y transitar de un modelo a otro, desplazamiento propio de los procesos de reterritorialización (simbólica, cultural y geográfica) que les ha tocado experimentar. El corpus considera producciones poéticas andinas actuales, amazónicas, guaraní y mapuche, entendidas en su conjunto como un polisistema literario indígena emergente.

\section{Corpus, repertorios y modelos de texto}

Los textos literarios no nacen, como dirá Promis (1977), por generación espontánea, sino que, por el contrario, «son productos del encuentro entre diversos códigos y que instauran un conjunto complejo de tensiones» (p. 13). Un corpus literario supone un conjunto de textos y autores que reúnen y comparten ciertas características (variables, por ejemplo, estéticas, geográficas, temporales) y que conforman un todo relativa y suficientemente homogéneo. Sin embargo, detrás de esa propuesta hay algo más que una lista, lo que hay es un «repertorio» (en la nomenclatura de la teoría de los polisistemas propuesta por Evan-Zohar, 1979) que reconoce un conjunto de reglas que están operando en los textos y que van a dar pie a propuestas de modelos de texto conservadores (es decir, se construyen siguiendo lo que el repertorio permite) o innovadores (cuando se rompen las reglas para transformarlo, resultando por lo tanto menos predecibles).

Referirnos a la poesía indígena supone la existencia y conocimiento de un corpus significativo de textos, lo que constituye un reto en múltiples sentidos. Primero, encontrar y reunir un conjunto de textos no resulta fácil por la limitación real de acceso a las obras. Nos referimos a una 
producción restringida respecto a su difusión y tiraje ${ }^{3}$, ya que suelen ser editoriales pequeñas o autoediciones con limitadas redes de distribución las que apuestan por estas publicaciones cuando son textos autoriales ${ }^{4}$. Otra complejidad se suscita cuando se quiere rastrear poemas dispersos en antologías y revistas literarias cuyos autores presentan un corpus literario de carácter fragmentario y asistemático. Este fenómeno se evidencia más en un comienzo en la producción de poetas mujeres, con menos oportunidad editorial y una incorporación más tardía al circuito literario. Todo ello conspira contra la generación de un sistema de preferencias por parte de los lectores que no conocen o acceden a esta producción. Segundo, porque al pensar en autores indígenas suponemos que deben ser representativos de sus culturas (muchas veces desde el imaginario de una estaticidad identitaria vinculada, preferentemente, a variables geográficas que tensionan y relevan la dupla urbano/rural, como metáfora de la relación modernidad/tradición) ${ }^{5}$, otorgándoles una carga simbólica difícil de sostener desde sus particularidades y subjetividades, aunque se tenga una experiencia colectiva y de comunidad. Y tercero, por una variable ya literaria: la desigual factura de muchos textos que dan cuenta de los diferentes momentos de producción poética, desde poemas primerizos leídos en recitales hasta la inclusión en diversas antologías o la adjudicación de reconocidos premios nacionales o internacionales (entendidos como instancias importantes de canonización).

Otro aspecto que enriquece la discusión, y que genera disenso entre algunos estudiosos, es la relación oralidad/ escritura, y la consideración como poesía indígena de textos de producción oral o etnoliteraria, y su adscripción al sistema poético (fenómeno estudiado por diversos críticos). En esta oportunidad nos centraremos en los textos poéticos escritos que entran en el radio de circulación de un sistema literario, sin dejar de reconocer el carácter poético que tiene el canto ancestral en sus propias lenguas y contextos de producción, como, por ejemplo, el canto de Brus Rubio, recopilador de su tradición y pintor amazónico uitoto-bora, o el canto en aimara de Pedro Humire en el norte de Chile.

3 Si bien internet permite acceder a información sobre los autores, no sucede lo mismo con su obra literaria, que se encuentra de manera fragmentada, textos aislados que no colaboran para una lectura de los proyectos poéticos.

4 Ulises Zevallos (2008) señala, para el caso de la poesía quechua, que las principales vías de publicación son las editoriales universitarias, las independientes, organismos no gubernamentales, municipios y ediciones en el extranjero, como Estados Unidos y Francia. Las posibilidades de visibilización de una producción narrativa y poética quechua permite que la propia lengua adquiera más estatus.

5 Pensemos, por ejemplo, lo que sucede en Ecuador con la literatura indigenista de la década de 1930, vinculada a una escritura costumbrista, de corte social y de la cual se quieren desmarcar las generaciones posteriores, autores provenientes de las grandes ciudades como Quito y Guayaquil. 
Como corpus acotado de este estudio, de textos poéticos escritos y adscritos al circuito literario, podemos suponer una variable estética que reconoce los distintos grados de maduración escritural y estadios de reflexión metatextual en los autores. En el caso de las literaturas indígenas contemporáneas nos encontramos con un repertorio emergente que se expresa mediante la introducción de elementos nuevos. No obstante, nos referimos a procesos que, si bien son dinámicos, pueden estabilizarse y sufrir solo cambios más paulatinos; «cuando un modelo primario se vuelve dominante en el repertorio y consiguientemente en el (poli)sistema, su perpetuación denota estabilización y nuevo conservadurismo» (EvanZohar, 1990, p. 14).

Al conjunto de obras, poéticas ${ }^{6}$, autores, sumados al contexto de producción y recepción, lo entendemos como un sistema poético indígena emergente ${ }^{7}$, que demanda una serie de condiciones o requisitos para su funcionamiento y posterior afianzamiento, que van desde la permeabilidad e influencia de otros sistemas literarios, hasta el proceso de constitución de su canonicidad, a través de la consolidación de un sistema de preferencias (Rodríguez, 2013). Reconocemos al menos ocho variables a tener en cuenta: 1) La generación de espacios propios (de producción, lugares de enunciación y difusión), debido a que como grupo cultural no encuentran los espacios para su propia expresión o no se sienten identificados con la cultura occidental y canónica. 2) La licencia de las influencias, al ser un sistema joven se permite la permeabilidad de elementos, estrategias y procedimientos desde otras culturas. La literatura indígena, particularmente la poesía, surge como una literatura derivada, su régimen natural es el de la hipertextualidad, para en una fase posterior retomar un curso de evolución que le es propio. 3) Se instala un repertorio vinculado a la producción restringida y alejada del campo de poder, por ubicarse fuera del canon, al margen de él, por tanto del circuito cultural hegemónico. 4) Los textos literarios promueven modelos de realidad, es decir, repertorios entendidos como el conjunto de reglas que están operando en los textos y que van a dar pie a propuestas de modelos de texto conservadores o innovadores. 5) Este nuevo sistema requiere de un espesor cultural (una historia en el ámbito de las manifestaciones artísticas y un corpus poético y crítico) que contemple: antecedentes etnoliterarios, es decir, un corpus

6 Gonzalo Espino (2007) hablará de una «etnopoética», es decir, la configuración de las prácticas verbales y escriturales andinas que tienen que ver con «el conflicto y la exclusión, por lo que una textualidad, quechua andina demanda una doble operación: la reposición y la puesta en valor del que casi siempre aparece como evento que profana el canon» (p. 180). 7 Esta propuesta está planteada de manera más extensa en el artículo de 2013 «Los espacios de la poesía indígena: agenciamientos y metatextos», en Taller de Letras, 52, pp. 157-174. 
de poetas precursores que se encuentren en transición entre la oralidad inscrita y la escritura poética propia, un repertorio de poetas actuales y un corpus crítico que estudie e investigue las poéticas en torno a estas literaturas particulares ${ }^{8}$.6) El carácter fundacional supone por parte de los poetas una reflexión metatextual (individual y colectiva) que colabore en la comprensión de la cultura y que sincere el espacio geopolítico desde donde se piensa y se enuncia. 7) Los poetas asumen una conciencia de "comunidad», es decir, de identidad común, y la experiencia de un relato compartido por todas las culturas indígenas que están en contacto. 8) Los poetas indígenas, sobre la base de una competencia cognitiva, pero también experiencial y afectiva, intervienen en las problemáticas de la comunidad y la sociedad; conciencia lúcida que tienen no solo de su proceso escritural sino de su compromiso cultural, ambiental y social.

\section{Modelos defensivos y transdiscursivos en los sistemas poéti- cos indígenas}

A partir del corpus de la poesía indígena podemos preguntarnos qué tipos de modelos están operando en cada cultura, cómo influyen los contactos con las literaturas canónicas particulares y si son fenómenos homogéneos, similares o diferentes.

La poesía indígena actual participa de una matriz que ofrece elementos comunes, entre ellos la tematización de aspectos como la lengua, la memoria y el territorio; siendo muchas veces el destinatario de esos textos un enunciatario dual (lector de ambos códigos) o un sujeto singular; de allí la intencionalidad de presentar los textos en versión bilingüe, en doble registro ${ }^{9}$ o, como dice la poeta guaraní Susy Delgado, «la palabra en dúo» («Esta palabra mía nacida en guaraní que halla su dúo en mi palabra castellana, porque observo de pronto que ellas hablan entre sí»). Para Iván Carrasco (2012), los escritores indígenas «no cesan de explicarle al otro quiénes son, cómo es su cultura, sus memorias, sus territorios, cuáles son sus semejanzas y diferencias, sus afectos y sus odios. Por ello, construyen tal vez sin saberlo, en muchos procesos de comunicación intercultural, discursos autoetnográficos» (p. 5); discursos a veces más cercanos a una función testimonial que a una función estética.

8 Respecto a la constitución de un corpus crítico se puede revisar el artículo de mi autoría de 2016, «Una crítica situada de la poesía indígena desde la suralidad: de las raíces a los ramajes». Revista Documentos Lingüísticos y Literarios, 33, pp. 67-78.

9 Los poetas están conscientes de la limitación de la traducción. Baltazar Azpur (1994), poeta quechua, señala en su libro Canto a la naturaleza «la traducción no equivale a una simple sustitución. Ciertos contenidos en castellano y quechua solo se corresponden parcialmente» (p. 187). 
En el sistema poético indígena actual reconocemos principalmente dos tipos de actitudes o modelos metatextuales disponibles y vigentes, uno de carácter defensivo y otro transdiscursivo, según categorías propuestas por Clem Robyns (1999) para la traducción cultural. Los poetas asumen ambas actitudes y suelen transitar de un modelo a otro.

\section{El modelo defensivo: resistencia y repliegue intracultural}

«Solo soy aquella semilla / puesta en la tierra por Ñande Ru Tenondé» Tu voz... semilla que nace / Germinando de la muerte En el silencio de tu danza. Brígido Bogado, poeta guaraní

El modelo o repertorio defensivo se caracteriza por una actitud que surge del resguardo de la propia identidad, del temor a la modificación de su espacio territorial, a la migración forzada y a la pérdida de la lengua y con ella de la cultura; por ello está más vinculado a los procesos de resistencia cultural y retradicionalización (como ha reconocido Mabel García, 2012). Corresponde este corpus, en la terminología de Iván Carrasco, a textos etnoculturales, cuyo enunciado se caracteriza por la estrategia de la intertextualidad transliteraria, entendida como la relación transtextual y dialógica del texto poético con otros discursos, tanto intraculturales (mitológico, de tradición oral, etc.) como interculturales. Ejemplos de intertexto intracultural encontramos en la alusión a los cantos, en su gama diversa, como el canto a la naturaleza en el poemario Phaqar Kirkio Cantos a las flores, de la poeta aymara Elvira Espejo («Flor de chhuchharapi / flor de chhuchharapi / Mi tiempo recién ha comenzado»); el canto ceremonial en María Clara Sharupi («Porque soy mujer Secha / llevo la palabra en mi corazón / porque soy mujer shuar / canto la canción de la siembra»), en el poema de Elicura Chihuailaf «Ruego en las paredes rocosas del cielo (Poema a la manera del canto de las machi)»; o en los versos del poeta guaraní Brígido Bogado, en una clara alusión al discurso cosmovisional de la búsqueda de la tierra sin mal: «iMi padre Avatupã! / Te ruego que reveles / al sueño inteligente del líder espiritual / el futuro del futuro porvenir». Desde el ámbito de lo sagrado se presenta la hoja de coca, del tabaco y de la ayahuasca o yagé, en textos como los poemarios Cábala para inmigrantes del poeta y yatiri aimara José Luis Ayala, Las hojas del poder, del escritor y antropólogo colombiano Fernando Urbina o los poemas de Anastasia Candre, escritora okaína-uitoto, «Mi pensamiento es sanación / Soplo con el poder de la palabra de la coca y del tabaco»,o el poema Yagé:

Yo soy el yagé...

Soy el espíritu que permanece de pie/Yo soy la sanación El dios de los sueños maravillosos 
Cuántas enfermedades he quitado con mi soplo

Mi palabra es de vida y de saberes...

Por otra parte, el intertexto intercultural que intensifica su especificidad subrayando la alteridad del discurso «extranjero» (del discurso oficial de la conquista, de la visión de los vencidos), lo podemos evidenciar en el siguiente fragmento del poema «Como Nantar y Namur», de la poeta amazónica shuar María Clara Sharupi:

Dedos mutantes que trajeron los conquistadores pretendieron confeccionar mi destino como el águila me deslicé bajo la piel del viento jíbara fue el nombre con el que me latiguearon ráfaga de municiones y pólvora fue la semilla en mi corazón...

Con un sentido similar encontramos el poema «Rebelión», de Leonel Lienlaf, que, como el propio título señala, es la reacción contestataria al sistema educativo nacional, formal y occidental, que pretende imponerse a la educación tradicional impartida por generaciones en las distintas comunidades indígenas: «Mis manos no quisieron escribir / las palabras / de un profesor viejo. // Mi mano se negó a escribir / aquello que no me pertenecía / Me dijo: / «debes ser el silencio que nace».

En relación con las literaturas nacionales, el modelo defensivo adoptaría una posición de repliegue y «distanciamiento», ya que se caracteriza por una actitud de diferenciación literaria y cultural respecto del sistema ajeno. Son textos reivindicativos, nostálgicos, de tono elegíaco o contestatario y de resistencia, con una toma de conciencia de la pérdida de los elementos ancestrales, y por ello con un fuerte gesto de intraculturalidad y reetnificación. En cuanto a las alusiones a sus cosmovisiones e identidades culturales, se refieren como temas recurrentes a la naturaleza, al buen vivir o vida buena (Sumak kausay en kichwa, Allin kausay en quechua, Suma qamaña en aymara, Shiir waras en ashuar, Tekó porã en guaraní, Küme mongen en mapuche), a la tierra sin mal guaraní (Yvymarae '̈̈), pero también al pachacuty, el torbellino cósmico, como los versos del poeta kichwa Ariruma Kowii:
El tiempo
el tiempo está convulsionado
el tiempo, tiene contracciones
el tiempo, puja, aprieta sus puños.

Este repertorio, además, alude a la conexión con los relatos míticos, recuperados a través de distintos mecanismos, como la inscripción, 
transcripción, adaptación o la reproducción homomórfica del discurso ritual (la misma estructura del relato mítico, que lo reconstruye o lo deconstruye), fenómeno estudiado por Julio Noriega (1995, pp. 151-152) para el caso quechua en el capítulo «El texto poético quechua moderno: escritura de mitos y rituales andinos»:

En distintos niveles de su configuración y realización, estos textos poéticos siguen patrones míticos y cumplen, hasta cierto punto, funciones que pertenecen a los rituales. La estructura interna de algunos textos tampoco deja de organizarse de acuerdo con una concepción mítica. Tanto el acto de creación poética como ciertas acciones y formas discursivas se realizan de manera análoga al funcionamiento de los rituales.

Un ejemplo de ello encontramos en el texto Hijo de aquel verbo, de Susy Delgado, texto que responde a la estructura y cosmovisión de los textos sagrados y cantos míticos guaraníes de Ayvu rapyta. Fundamento de la palabra. De igual manera, se alude al relato mítico de origen kichwa en el poemario de Ariruma Kowii Tsaitsik. Poemas para construir el futuro, como se puede apreciar en los siguientes versos:

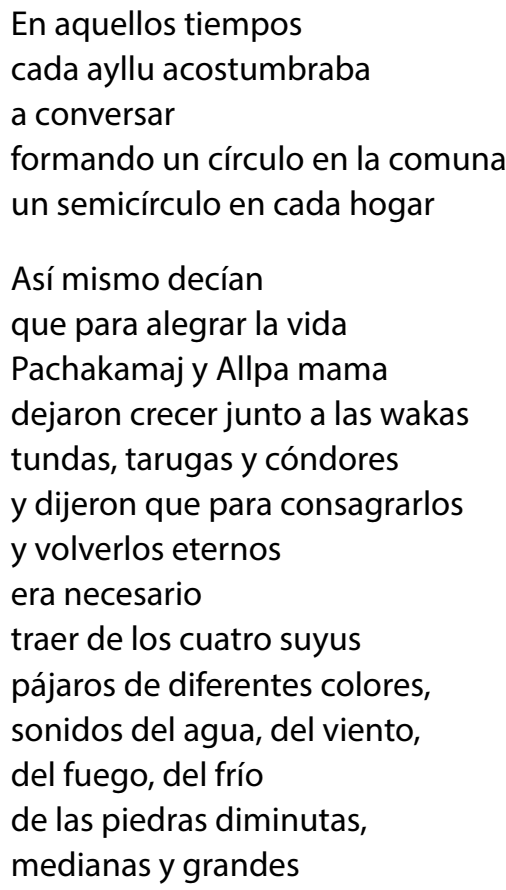

Otro intertexto al que alude este modelo es al canto tradicional como lugar de enunciación colectiva y en clave indígena: üll, purahéi, kirki, taki, 
huaynos, harawis, jaillis, rondines, ícaros, anent, son géneros propios; algunos de ellos, los cantos sagrados, se mantienen resguardados en su cultura; otros se transcriben y reescriben actualizando las formas discursivas de la poesía prehispánica, pero desde un sujeto autorial (ya no anónimo), respetando las reglas versales y rítmicas del género. Ejemplo de ello encontramos en el texto Jarawi de Dida Aguirre; Canciones aymaras, del poeta y narrador Felipe Huayhua; en Magütagü arü wiya. Cantos tikuna, de Lucía Cuéllar; o los cancioneros guaraníes, particularmente las guaranias, de José Asunción Flores, Manuel Ortiz Guerrero o Teodoro Mongelos.

Muchos poemarios son cantos a elementos de la naturaleza («Nombrar a un pájaro es cantar con él», dirá Humberto Ak'abal), como Canto de la tierra, del guaraní Brígido Bogado; Canto a las flores, de la poeta aimara Elvira Espejo; Canto a la naturaleza, del quechua Baltasar Azpur; o el poemario enteramente en quechua, de Godoy Félix Yauri Taipe, Musuq punchaw. Harawi (cantos de vida).

La relación con la naturaleza se ve tensionada cuando ella muta, cuando es violentada, transformada, consumida; extrañamiento y ajenidad de las que dan cuenta los poetas, cuestionando el antropocentrismo de la cultura occidental que coloca al ser humano por encima de la naturaleza. El sujeto poético encuentra estrategias para restablecer esa relación consubstancial, asumiendo, por ejemplo, desde la voz de un sobreviviente la tozudez de la persistencia. Ejemplos de ello son los versos de la poeta mapuche María Isabel Lara Millapán: «hemos de permitir germinar el bosque / y anidar en la tierra nuestro espíritu / para volver a vivir cerca de los ríos». Esta voz de un sobreviviente es la conciencia de una identidad que se reafirma en ese gesto defensivo, pero también colectivo y plural, como en Versos de sal, de la poeta uitoto Yenny Muruy Andoque:

Mi voz no es solo mía. De mi gente, la palabra que viene renaciendo, yo soy la portavoz. Aunque joven, mujer, madre, en mí resuena una voz que viene desde antiguo, palabra que no muere...

Igualmente es defensiva la actitud en los textos poéticos que restituyen el poder de la palabra. En esta línea están los poemarios de Ariruma Kowii Poemas para construir el futuro, y Despierten las palabras. Tuyu nde ajho'i, che retã, de Félix de Guarania: «iDespierten las palabras! / Se alce el canto maduro [...] / Acuda el grito, / Óiganse las roncas voces / de la ira / y el anónimo verbo de la lucha», o el poemario Danzantes del viento, de Hugo Jamioy («La poesía / es el viento que habla / al paso de las huellas antiguas»). 
El grito se erige como estrategia de resistencia, como catarsis en los libros en doble registro quechua y castellano, en Kaparikuy/Grito, de Dida Aguirre, y Urqukunaq qapariynin. Alarido de Montaña, de Washington Córdova $^{10}$, y el texto mesiánico, lo que ha llamado Lienhard (1988) el pachacuty taki, es decir, canto y poesía como transformación del mundo. Ejemplifica estos universos poéticos cataclísmicos expresados en quechua con Eduardo Ninamango Mallqui (Pukutay), Dida Aguirre (Poemas quechuas) e Isaac Huamán Manrique (Nanay).

La resistencia se expresa además desde otra trinchera, la urbana, como hacen los poetas mapuche David Añiñir (Mapurbe), Eliana Pulquillanca (Azul gris. Palabra e imagen mapuche en la ciudad) y César Millahueique, quienes asumen la voz de un sujeto migrante, marginal y marginado por la sociedad, pero, paradojalmente, restituido y relevado por el oficio de la palabra. Es el caso de Eliana Pulquillanca en su poema Ruka «Aquí en medio de los fierros / crece la totora. / Crece, se empina / Cual águila buscando su carne / En este bosque de polvo / Sin miedo y con epew en los labios». En Profecías en blanco y negro, de César Millahueique, el sujeto se siente un sobreviviente al experimentar la brutal condición desterritorializada de la migrancia.

Otros autores que actualizan este repertorio son los poetas quechuas Ch'aska Anka Ninawaman, Feliciano Padilla, Gloria Mendoza Borda; los kichwa Ariruma Kowii, Lucila Lema, Wary Silvia Vásquez, Lourdes Llasag Fernández y Luz Aurora Chinlle Vacacela; de la nación aimara Dante Nava, Pedro Humire, Regina Puma, Clemente Mamani, Elvira Espejo, Nélida Flores, Zacarías Alavi Mamani, Juan de Dios Yapita, Filomena Nina Huarcacho y Bertha Villanueva (esta última del movimiento katarista de Bolivia); los guaraníes Manuel Ortiz Guerrero, Félix Fernández de Guarania y Miguel Ángel Meza, y de los pueblos amazónicos Anastasia Candre, Lucía Cuéllar, Yenny Muruy Andoque, Hugo Jamioy, Raquel Yolanda Antún, María Clara Sharupi, Dida Ananco; los mapuches Elicura Chihuailaf, Leonel Lienaf, Adriana Paredes Pinda, María Teresa Panchillo, Maribel Mora, Graciela Huinao, María Isabel Lara Millapán, Liliana Ancalao, y Juan Huenuán, entre muchos otros.

En esta tipología textual, sin embargo, la estrategia más defensiva e intracultural que podemos encontrar es la escritura poética monolingüe de poemarios, antologías o revistas, a través de actitudes lingüísticas que relevan las lenguas maternas; recurso que tiene como objetivo

10 Desde la crítica literaria encontramos el texto Grito geo-histórico o lamento utópico del indio, del ecuatoriano Luis Antonio Quizhpe (2004), ensayo sobre el conocido poema Boletín y elegía de las mitas, de César Dávila Andrade. 
captar nuevos destinatarios, nuevos lectores que generen un nuevo sistema de preferencias. Son autores que no sienten la presión ni el interés de llegar a un público que no participe de su cultura o no hable la lengua, sino el gesto político a que la aprendan. Un claro ejemplo lo constituye Riwista Atuqpa Chupan en quechua, revista literaria de los estudiantes de la Universidad Nacional Mayor de San Marcos del Perú; la revista AYVU de Paraguay, escrita exclusivamente en lengua guaraní y que pretende ser un instrumento para la difusión de textos escritos en esta lengua; o la antología de tradición oral y poesía en kichwa de Ecuador Kichwakunapa Yachaykuna. También únicamente en quechua encontramos los poemarios de Kilku Waraka Taki parwa, de Godoy Félix Yauri Taipe; Musuq punchaw. Harawi, de Ugo Carrillo Cavero; Yaku ukuna yuyaynin y Puyupa-wayrapaninapawan-musqukusqanmanta (runapa siminpi quilqakuna), entre otros; y en guaraní, Che Kirĩri asapukái haguã, libro de poemas de Carlos Abente. Desde la disciplina de las ciencias sociales están los textos en aimara como Aymara Mayjt'a Arunaka, de José Luis Marquez Maidana; Aymara Sawunaka, de Justino Callisaya Acero; y Qarwanakampi sarnaqirinakata Machaqa tuqina, de Máximo Quisbert Q.

La función sociocomunicativa de los textos monolingües permite distintas y complejas relaciones con su público lector. Estos textos constituyen un desafío tanto para el lector monolingüe en su lengua materna que, a pesar de tener un alto conocimiento de su tradición oral, no tiene necesariamente una cultura literaria «escrita», o incluso no maneja el mismo alfabeto del autor. Por otro lado, el lector con una mayor competencia literaria «occidental», no conoce la lengua (y por tanto las claves culturales). Para ambos tipos de destinatarios, estas limitaciones invitan a tornarse en un lector activo, capaz de completar los vacíos del texto, de la lengua, del contexto y la tradición cultural.

\section{El modelo transdiscursivo: diálogo y despliegue intercultural}

Pariaqaqa y su mancha tocan su tambor/ en los corrales del logos

Cuscomantachus ....

Limakamachus?

Irá rodando

Chawpin tarinanchiqpaq?

Su Ra

Esa música llegada al rito por los bordes de la libertad

But the hunger of Faustos

tiene hoyos inmensos

chunniqllanã kakullachkan

Fragmento de Poema del jazz y variaciones paisanas

Fredy Roncalla, poeta quechua 
Este modelo de texto corresponde a una propuesta de carácter más innovador y transgresor, dada principalmente por la permeabilidad de influencias de otras culturas y tradiciones literarias. Las posibilidades de este repertorio se amplían significativamente en la medida en que el poeta puede hacer uso de problemáticas, géneros, estilos, provenientes de la poesía occidental, sin dejar por ello de ser poeta indígena. Los poetas que experimentan estas influencias han sido ellos mismos sujetos migrantes, parte de la «diáspora indígena», translocación territorial, simbólica e idiomática ${ }^{11}$, a través de un proceso por el cual el sujeto va conformando un discurso descentrado, heterogéneo, múltiple, que enuncia y traduce una biculturalidad con elementos antagónicos que no se resuelven ni sincrética ni sintéticamente. La condición de sujeto migrante letrado lo hace apropiarse de la cultura, escritura y lengua ajenas, y llega incluso, como señala Roncalla, a sentirse un sujeto multiterritorial (no resta lugares ni experiencias, sino que suma). Julio Noriega (2011) señala que la situación de los escritores indígenas y mestizos del periodo colonial se repite en los poetas quechuas contemporáneos «igual que sus antecesores, han ensayado múltiples formas de integración en la moderna sociedad urbana antes de ponerse a escribir. Para sobrevivir como migrantes, exiliados del mundo andino, se vieron forzados a recurrir a diferentes formas de encubrimiento cultural, de negación de su propia identidad» (p.106). A diferencia de la migración andina hacia la urbe, la experiencia migrante amazónica se valdrá precisamente de su identidad cultural para insertarse en la ciudad (Vega, 2013) ${ }^{12}$. Pareciera que más que un encubrimiento o negación de su identidad lo que encontramos es un fenómeno de reterritorialización, a partir de ciertas estrategias en las que los poetas incorporan a su cultura elementos ajenos, provenientes del nuevo espacio que habitan, lo que Bonfil Batalla (1988) denomina «la cultura apropiada»:

Este ámbito se forma cuando el grupo adquiere la capacidad de decisión sobre elementos culturales ajenos y los usa en acciones que

\footnotetext{
11 Herrera dirá: «Me parece también necesario subrayar que el imaginario del migrante está profundamente articulado a un mundo simbólico y a formas culturales específicas; por ello, podemos afirmar que esa ciudad, individualmente percibida y practicada, es, a pesar de todas sus variaciones, la ciudad vivida del migrante indígena y no la de cualquier otro habitante de la urbe. Esto no significa que ese mundo simbólico permanezca inalterado en el contexto urbano: la interacción con la ciudad produce cambios y readecuaciones» (p. 15). 12 Buscando el río es el título del libro de Ismael Vega, que muestra cómo se va reinventando lo amazónico en la ciudad de Lima, «los migrantes indígenas amazónicos tienen en la pertenencia étnica el referente más importante para reinventar sus identidades y establecer sus relaciones sociales. Compartir un pasado común y la conciencia de pertenencia a un mismo pueblo y un mismo territorio son elementos que siguen vigentes en la ciudad» (p. 50). Todos expresan y reivindican abiertamente su identidad étnica cultural, ningún migrante ha buscado ocultar su identidad. Los indígenas amazónicos, consideran que la identidad étnica es un factor fundamental en su estrategia para insertarse en la ciudad (p. 104).
} 
responden a decisiones propias. Los elementos continúan siendo ajenos en cuanto el grupo no adquiere también la capacidad de producirlos o reproducirlos por sí mismo; por lo tanto, hay dependencia en cuanto a la disponibilidad de esos elementos culturales, pero no en cuanto a las decisiones sobre su uso (p. 27).

En este sentido, apropiarse de la lengua ajena («tomar por asalto el castellano», dirá la estudiosa Virginia Ayllón (2007) sobre el poeta aimara boliviano Clemente Mamani), posibilita que el sujeto reconvierta sus saberes y producciones en el ámbito urbano de manera multidireccional, no solo como estrategia de resistencia, sino como propuesta estética al escribir en castellano andino; con vocabulario castellano, pero con estructura sintáctica y lógica andina, lo que da como resultado ya solo con ese gesto, con ese uso, un producto poético innovador, como los versos de Clemente Mamani: «En la sagrada sobrevivencia / todo explotan con un arambel / de sistemas foráneos».

El repertorio transdiscursivo integra al propio sistema no solo elementos de la cultura dominante, sino también procedimientos poéticos, estrategias y recursos de otras disciplinas. Este agenciamiento es definido por su diálogo e intercambio con otros sistemas y tradiciones culturales y literarias. Supone también que supera la determinación de los vínculos de la poesía indígena con la tradición oral, para asumir, de manera natural, una relación dialógica con otras literaturas y manifestaciones artísticas contemporáneas. José Antonio Mazzotti (2002) se referirá a las fragmentaciones migratorias, señalando que lo que define como poéticas del flujo no es solo en función de los movimientos migratorios sino también flujos, trasvases y tránsitos sociales, verbales y rítmicos, por los «pliegues textuales mediante los que tales fenómenos «externos» al poema se transforman originalmente, dando cuenta según cada autor de manejos del lenguaje poético sui géneris dentro de una larga y prestigiosa tradición» (p. 15).

Los poetas pueden reescribir y resignificar su propia memoria cultural y su tradición (como hace la mapuche Roxana Miranda Rupailaf en Shumpall), pero al mismo tiempo recurrir a los registros de otras escrituras y a las estrategias de otras disciplinas por la que transitan, por ejemplo, en Vírgenes urbanas, una propuesta fotopoética de Odi Gonzales y la artista Ana de Orbegoso, que corresponde a la exposición itinerante de fotos de gran formato y a la vez catálogo y poemario en tres lenguas. Encontramos la misma heterogeneidad textual en la mayoría de los textos del escritor aimara José Luis Ayala y en particular en Cábala para inmigrantes y en $\mathrm{Ce}$ lebración cósmica de Rita Puma, texto híbrido que conjuga testimonios, documentos, fotografías, entrevistas, poemas, retratos, con el fin de dar 
cuerpo y forma a la imagen ya difusa y desdibujada de la joven activista aimara asesinada Rita Puma.

Interesante es la conexión que hace Pedro Shimose, poeta amazónico boliviano, entre poesía y canto popular, al componer canciones con el ritmo tradicional de esa zona, taquiraqui (como «Adiós mi Riberalta»), que es un ritmo musical folclórico y una danza de Bolivia, característico de la mayor parte de los departamentos de Santa Cruz, Beni y Pando en la zona oriental del país. Esta relación con otras manifestaciones puede ser también con otras más propias del mundo moderno, como la fotografía en los libros de Fernando Urbina, especialmente sus fotopoemas.

Los ejemplos más notables de esta actitud transdiscursiva los encontramos en los guaraníes Mario Rubén Álvarez y Susy Delgado; los quechua Fredy Roncalla, Odi Gonzales y Washington Córdova; y Efraín Miranda y José Luis Ayala para el caso aimara; los mapuches Jaime Huenún, Roxana Miranda, Bernardo Colipán, César Millahueique.

Los poetas adoptan nuevas estrategias escriturales y hacen uso de la doble codificación lingüística, de collages etnoculturales y desde el punto de vista artístico se hibridan con otras disciplinas y géneros. Un claro ejemplo de estas interferencias propias del diálogo corresponde a la identificación, asunción o adscripción de las vanguardias, neovanguardias y posvanguardias en poetas como el mapuche César Millahueique, el quechua Freddy Roncalla, el aimara Efraín Miranda y los puneños Gamaliel Churata, Inocencio Mamani, Omar Aramayo Cordero, Alejandro Peralta y Boris Espezúa Salmón ${ }^{13}$, o, en el caso de las poéticas amazónicas, la poesía concreta en Homero Carvalho, de ascendencia movima, de la región de Beni de Bolivia.

Corresponderían también a este modelo, por los cruces disciplinares, los textos poéticos que utilizan estrategias provenientes de la etnografía, para elaborar propuestas más cercanas a lo que Iván Carrasco (2012) denomina literatura antropológica, entendida como una:

textualidad compleja que conforma un tipo nuevo de mutación disciplinaria entre la literatura y las ciencias humanas, y de escritura

\footnotetext{
13 Sobre la poesía puneña encontramos interesantes trabajos como Cinco poetas puneños, de Renán Espezúa Salmón (2011), antología crítica que delimita el corpus con Carlos Dante Nava, Alejandro Peralta Miranda, Carlos Oquendo de Amat, Efraín Miranda Lujan y Boris Espezúa Salmón. El libro Poéticas andinas. Puno, de Mauro Mamani (2009), es un riguroso estudio crítico con interesantes tesis sobre los proyectos poéticos de Inocencio Mamani, Carlos Oquendo de Amat, Efraín Miranda, Omar Aramayo, José Luis Ayala, Gloria Mendoza Borda y Boris Espezúa Salmón. Otra antología crítica es Aquí no falta nadie. Antología de poesía puneña, de Walter Bedregal (2008), que reúne a 21 poetas; texto algo más polémico (por lo imperdonable de ciertas ausencias como Gamaliel Churata, Dante Nava o José Luis Ayala), pero relevante, por la inclusión de autores más recientes.
} 
fronteriza, que persigue funciones cognitivas, testimoniales o autobiográficas. En su horizonte de expectativas se encuentra un sistema de recepción intercultural, formado por lectores y enciclopedias culturales de carácter europeo, indígena y chileno (p.3).

Ejemplifica esta particular modalidad con Epu mari quiñe ülcatun, de Pedro Alonzo Retamal, de 1970. En esta línea, por su carácter testimonial y autobiográfico, podemos leer también como poesía etnográfica al texto La matanza de Forrahue 1912, del poeta e historiador Bernardo Colipán, y escrito en conjunto con la comunidad de Forrahue; a la aimara boliviana Ana María Condori, con Nayan uñatatawi: Mi despertar, texto poético testimonial; y al quechua Freddy Roncalla, con los textos Hawansuyo ukun words, recorrido poético y vivencial que dibuja en su trayecto la poética espacial de los lugares del Ande (lugares geográficos, pero también de rituales y de la memoria, por tanto del afecto) y Escritos mitimaes. Hacia una poética andina postmoderna, este último en lengua quech-spanglish (dirá Alex Julca en la presentación), y que corresponde a una serie de ensayos y poemas escritos desde el hemisferio norte, y cuyo distanciamiento le posibilita reflexionar sobre la migrancia, los límites del ámbito cultural de los Andes y su extensión que sigue patrones de multiterritorialidad que permiten la adaptación de los sujetos andinos.

Otra experiencia fronteriza es la de Homero Carvalho, escritura en permanente búsqueda y experimentación polifónica, multimodal, que sin embargo se ancla en su experiencia vital de vivir en los dos mundos que conoce en profundidad. El sujeto poético amazónico asume el compromiso y el rol de resguardar y transmitir sus memorias, desde las voces polifónicas, por ejemplo, de un narrador de mitos de creación movima en Los reinos dorados; o de un paketpas, que son los guardianes de la tradición y de los sueños, en Cazador de sueños; o de un quipucamayo en el poemario Quipus, texto plurigenérico que trabaja desde la poesía concreta, inspirada por una forma poética que juega con lo visual y lo espacial.

Oscar Galindo (2010), a propósito de las vanguardias y neovanguardias en Latinoamérica, ha señalado que con estos procedimientos transdisciplinares emerge un nuevo realismo que reprocesa el realismo tradicional por medio de nuevas formas de representación y de testimonialidad poéticas. Según Carrasco (2002), se trata de un nuevo tipo de género discursivo, de carácter híbrido; modalidad textual específica surgida en el conjunto de las posibilidades abiertas por la interdisciplinariedad en el discurso contemporáneo y que adquirirá diferentes denominaciones, como mutación disciplinaria (Carrasco, Galindo), discursos fronterizos (Verónica Galván, 2002), literaturas posautónomas o escrituras diaspóricas (Josefina Ludmer, 2006). Todas ellas apuntan a transgresiones genéricas o géneros 
híbridos como propuestas innovadoras en el campo de los discursos literarios contemporáneos; seducción de la cual no están exentas las poéticas indígenas (particularmente la puneña), como el experimentalismo en las obras de Gamaliel Churata, El pez de oro y Resurrección de los muertos ${ }^{14}$.

\section{A modo de conclusión (entre despliegues y repliegues)}

«Como una ola que recoge lo que está en la orilla antes de volver al $\operatorname{mar}^{15}$

El sistema poético indígena actual presenta dos tipos de modelos textuales o repertorios a los que hemos denominado defensivo y transdiscursivo. Estos modelos están dando cuenta de una identidad discursiva; esto es, una identidad sociocultural a través de determinadas prácticas textuales. Entre estas propuestas transitan de manera dinámica los escritores indígenas, con poéticas y modelos que muestran una condición heterogénea, definida en buena medida por los mecanismos de apropiación de la tradición literaria occidental y de la incorporación de la tradición oral indígena. El modelo defensivo comporta una memoria histórica y arrastra con ella la tozudez por no olvidar, articulando un discurso de resistencia y repliegue intracultural frente a la cultura oficial dominante ${ }^{16}$. Las estrategias textuales serán diversas, pero la herramienta más poderosa es la lengua materna y más aún la escritura (y recitado) monolingüe. Esta opción ideológica y cultural supone elegir la confrontación y manifestar su etnicidad en contra de los modelos dominantes, creando públicamente (como señala Makaran, 2008) una cultura alternativa.

Respecto a la actitud transdiscursiva los poetas indígenas contemporáneos, «letrados», es decir, con una competencia y formación literaria adscrita al circuito occidental, retomarán esta vertiente de textualidad multifacética, influenciados además por nuevas corrientes literarias en las cuales se han formado, particularmente con la tradición vanguardista y neovanguardista.

El dinamismo de ambas actitudes, por tanto la experiencia de ambos modelos, hará que algunos poetas se apropien de un tipo de repertorio,

\footnotetext{
14 Para Antonio Melis (2010) ambas obras de Churata subvierten el lenguaje heredado de la tradición cultural hegemónica En 2012, la revista de literatura La Mariposa Mundial, importante publicación boliviana en la materia, le dedica íntegramente dos números (19 y 20) a Gamaliel Churata. Arturo Vilchis señala en la presentación que ambos textos son «partes de una obra más extensa, que se entornan subversivas, porque deforman los parámetros de lo escritural ordinario»

15 Expresión de Mauro Mamani en una conversación informal, en Lima, en 2011, al referirnos a los repliegues y despliegues de las literaturas indígenas.

16 Makaran (2008) dirá para el caso andino: «Las etnias andinas solían reaccionar de diferentes maneras, según las condiciones históricas: retirarse con su etnicidad a los hábitos privados y cultivar su tradición fuera de la corriente oficial» (p. 129).
} 
como el poeta que se desplaza desde el modelo transdiscursivo al defensivo, para decantar en una poética libre de seducciones y marcas que ya no siente propias (como la misma escritura, un determinado alfabeto o la lengua castellana); toma de conciencia que va, como señala Gonzalo Espino, de un aprendizaje a un reaprendizaje, a una poesía india, que incluso se desprende de las estrategias poéticas, para retornar y recuperar el canto ancestral. 


\section{REFERENCIAS BIBLIOGRÁFICAS}

AYLLÓN, V. (2007). Aruskipasipxañanakasakipunirakispawa. Notas sobre dos poetas indígenas bolivianos contemporáneos. Revista Nuestra América, 3, pp. 67-77.

AZPUR, B. (1994). Canto a la naturaleza. Ayacucho: Graph.

BEDREGAL, W. (2008). Aquí no falta nadie. Antología de poesía puneña. Lima: LagOculto.

BONFIL BATALLA, G. (1988). La teoría del control cultural en el estudio de procesos étnicos. Anuario Antropológico, 86, pp. 13-53.

CARRASCO, I. (2002). Interdisciplinariedad, interculturalidad y canon en la poesía chilena e hispanoamericana actual. Estudios Filológicos, 37, pp. 199-210.

(2012). Escritura antropológica en la poesía mapuche. Ponencia, V Congreso Internacional de Lenguas y Literaturas Indoamericanas (pp. 1-19). Temuco.

CORNEJO POLAR, A. (1982). Sobre literatura y crítica latinoamericanas. Caracas: Ediciones de la Facultad de Humanidades y Educación de la Universidad Central de Venezuela.

ESPEZÚA SALMÓN, R. (2011). Cinco poetas puneños. Puno: Grupo Huajsapata.

ESPINO RELUCÉ, G. (2007). Etnopoética quechua. Textos y tradición oral quechua (tesis de doctorado). Universidad Nacional Mayor de San Marcos, Lima.

EVEN-ZOHAR, I. (1979). Polysystem Theory. Polysystem Studies [=Poetics Today, 11(1-2), pp. 287-310.

GALINDO, O. (2010). El lugar de lo real: la poesía del cono sur en los años sesenta. Estudios Filológicos, 45, pp. 23-33.

GALVÁN, V. (2002). Discursos fronterizos. Diálogos Latinoamericanos, 6, pp. 21-31.

GARCÍA, M. (2012). El proceso de retradicionalización cultural en la poesía mapuche actual: Üi de Adriana Paredes Pinda. Revista Chilena de Literatura, 81, pp. 51-68.

HERRERA MONTERO, L. (1999). La ciudad del migrante: la representación de Quito en relatos de migrantes (tesis de maestría). Universidad Andina Simón Bolívar, Quito.

LIENHARD, M. (1988). Pachakutiy Taki: canto y poesía quechua de la transformación del mundo. Allpanchis, 20 (32), pp. 165-195. 
LUDMER, J. (2006). Literaturas postautónomas de hoy. En Semana de las Humanidades. Instituto Tecnológico de Monterrey, Ciudad de México.

MAKARAN, G. (2008). Bolivia, una wawa criolla: la realidad nacional boliviana en la literatura indígena desde los tiempos coloniales hasta los años 70 del siglo XX. Estudios Latinoamericanos, 28, pp. 93-133.

MAMANI MACEDO, M. (2009). Poéticas andinas/Puno. Lima: Instituto de Investigaciones Humanísticas IIH, Facultad de Letras de la Universidad Nacional Mayor de San Marcos, Pájaro de Fuego.

MAZZOTTI, J. A. (2002). Poéticas del flujo: migración y violencia verbales en el Perú de los 80. Lima: Fondo Editorial del Congreso del Perú.

MELIS, A. (2010). El obscuro de Puno. Gamaliel Churata. Resurrección de los muertos (Ricardo Badini, Ed.). Lima: Asamblea Nacional de Rectores.

NORIEGA, J. (1995). Buscando una tradición poética quechua en el Perú. Miami: Centro Norte-Sur.

(2011). Escritura quechua en el Perú. Lima: Pakarina Edi-

ciones.

QUIZHPE, L. A. (2004). Grito Geo-histórico o lamento utópico del indio del ecuatoriano. Loja: Casa de la Cultura Ecuatoriana Benjamín Carrión.

PROMIS, J. (1977). Testimonios y documentos de la literatura chilena (18421975). Santiago: Nascimiento.

ROBYNS, C. (1999). Traducción e identidad discursiva. En M. Iglesias Santos (Coord.). Teoría de los polisistemas (pp. 281-309). Madrid: Arco.

RODRÍGUEZ MONARCA, C. (2013). Los espacios de la poesía indígena: agenciamientos y metatextos. Taller de Letras, 5, pp. 157-174.

(2016). Una crítica situada de la poesía indígena desde la suralidad: de las raíces a los ramajes. Documentos Lingüísticos y Literarios, 33, pp. 67-78.

VEGA, I. (2013). Buscando el río. Identidad, transformaciones y estrategias de los migrantes indígenas amazónicos en Lima Metropolitana. Lima: Terra Nova.

VILCHIS, A. (2012). Entre las alas de una mariposa de obsidiana. La Mariposa Mundial, 19-20, pp. 1-5.

ZEVALLOS, U. (2008). Gestión cultural en los Andes. Literatura quechua hoy. Lhymen. Cultura y Literatura, 5, pp. 7-22. 